\title{
Seasonal variability of prooxidant pressure and antioxidant adaptation to symbiosis in the Mediterranean demosponge Petrosia ficiformis
}

\author{
F. Regoli ${ }^{1, *}$, C. Cerrano ${ }^{2}$, E. Chierici ${ }^{1}$, M. C. Chiantore ${ }^{2}$, G. Bavestrello ${ }^{3}$ \\ ${ }^{1}$ Istituto di Biologia e Genetica, Università Politecnica delle Marche, Via Ranieri, Monte D'Ago, 60100 Ancona, Italy \\ ${ }^{2}$ Dipartimento per lo Studio del Territorio e delle sue Risorse, Università di Genova, Via Balbi 5, 16126 Genova, Italy \\ ${ }^{3}$ Dipartimento di Scienze del Mare, Università Politecnica delle Marche, Via Brecce Bianche, 60100 Ancona, Italy
}

\begin{abstract}
In symbioses between invertebrates and microalgae, host tissues are exposed to increased levels of photosynthetically produced oxygen. The biochemical consequences of symbioses have been poorly investigated in Mediterranean species, but a general increase in antioxidant defences has been recently reported in the demosponge Petrosia ficiformis as an adaptive response to the cyanobacterium Aphanocapsa feldmanni. Since Mediterranean symbioses naturally experience marked seasonal variations in symbiont content, light intensity and seawater temperature, the aim of this work was to investigate if these fluctuations modulate the prooxidant challenge to sponge tissues. Antioxidant efficiency was characterised on a monthly basis by combining an analysis of the main antioxidants (superoxide dismutase, catalase, glutathione S-transferases, glutathione reductase, glutathione peroxidases) with measurements of the total oxyradical scavenging capacity (TOSC), thus achieving a more holistic assessment of the capacity of sponge tissues to absorb different forms of reactive oxygen species. Symbiotic sponges showed significant seasonal changes in antioxidant efficiency, with more marked variations in tissues directly exposed to photosynthetically produced reactive oxygen species. The greatest variations were observed during the summer months, with the highest seasonal values for some defences (i.e. catalase) and the lowest for others (i.e. glutathione peroxidases). The marked increase in catalase and TOSC in summer suggests greater production of $\mathrm{H}_{2} \mathrm{O}_{2}$ in the symbioses during this period, supporting the hypothesis that seawater temperature can significantly modulate the prooxidant challenge in Mediterranean symbioses. The results suggest that species with lower antioxidant efficiency may be less tolerant of conditions effecting oxidative damage; e.g. increases in temperature during the summer months.
\end{abstract}

KEY WORDS: Mediterranean symbioses · Oxyradicals · Antioxidants · Adaptation · Sensitivity · Temperature $\cdot$ Demosponge

\section{INTRODUCTION}

Symbioses have been largely described between photosynthesising organisms (e.g. cyanobacteria and dinoflagellates, diatoms and algae) and several marine invertebrates including poriferans, cnidarians, ascidians and molluscs (Douglas 2003). These associations, particularly frequent in tropical coral reefs, have also been reported from temperate and even polar environments (Shick \& Dykens 1985, Dunlap \& Shick 1998, Cerrano et al. 2000a, 2003).
Photosynthetic products secreted by the symbionts represent an additional food source for the host tissues, while benefits for microalgae include the use of animal waste for nutrients, exposure to light and a protected habitat during their life cycle (Trench 1993). An association with algae is thought to be necessary for some species such as adult giant clams, which are never devoid of zooxanthellae, while in other organisms the presence of symbionts is influenced more by physical and environmental factors like depth-dependent light irradiance and tempera- 
ture, and seasonal fluctuations in these parameters (Shick et al. 1996).

Considerable interest has developed in the biochemical consequences of symbioses to invertebrate tissues, which are exposed to increased levels of oxygen produced during photosynthetic processes. These reactions involve the generation of reactive oxygen species (ROS) such as $\mathrm{O}_{2}^{-}, \mathrm{H}_{2} \mathrm{O}_{2}$ and $\cdot \mathrm{OH}$, the formation of which is considered proportional to the partial pressure of molecular oxygen, $\mathrm{pO}_{2}$ (Jamieson et al. 1986). Several studies on tropical invertebrates have revealed increased efficiency of antioxidant defences in response to symbionts, and variations in such defences have been measured in organisms collected along depth transects or exposed under field and laboratory conditions to different regimes of light and temperature, both of which factors are well known to influence the generation of oxyradicals (Lesser et al. 1990, Shick et al. 1995, Douglas 2003).

In such symbioses, ROS are mainly produced within the chloroplasts by several mechanisms associated with the electron transport chains of Photosystems I and $\mathrm{II}_{i}$ among these, hydrogen peroxide $\left(\mathrm{H}_{2} \mathrm{O}_{2}\right)$ is generated in the Mehler reaction by the oxygen-evolving complex (Mehler 1951, Badger 1985, Richter et al. 1990), and from the algae cell this molecule can easily diffuse into the host cytoplasm (Downs et al. 2002). If not adequately neutralised by antioxidant defences, hydrogen peroxide can induce direct oxidative damages or react with superoxide anion and/or transition metals to originate the hydroxyl radical $(\cdot \mathrm{OH})$, by far the most toxic and reactive oxyradical.

In symbiotic corals, it has been proposed that antioxidants can compensate the algae-induced prooxidant pressure within a certain threshold of ROS concentration. Above this threshold, the increased antioxidant efficiency can be overstretched by ROS production, and oxidative damage will occur. The 'oxidative theory of coral bleaching' proposes that bleaching is the final defence of corals against oxidant injury (Downs et al. 2002): when algal production of oxyradicals is exacerbated (i.e. by elevated temperature), corals will remove the main source of oxidative damage by expelling their endosymbiotic algae.

In coral ecosystems, symbioses are also greatly affected by temperature variations, and increased sea surface temparature has been associated with mass coral bleaching events (Lesser 1996, 1997, Stone et al. 1999, Wilkinson 1999, Douglas 2003). In different colonies of the star coral Montastera annularis, accumulation of oxidative damage products, antioxidants and cellular stress capacity were correlated with increases in temperature and coral bleaching intensity (Downs et al. 2002) confirming that high temperatures may contribute to triggering oxidative stress and bleaching in coral reef systems (Lesser et al. 1990, Dykens et al. 1992, Goreau \& Hayes 1994, Downs et al. $2000,2002)$. Anomalous seawater temperatures lead to bleaching events also in the Mediterranean corals Cladocora caespitosa, Balanophyllia europea and Oculina patagonica (Metalpa et al. 2000, Kushmaro et al. 2001). Several species of sponges and gorgonians underwent a strong mass mortality during summer 1999 (Cerrano et al. 2000b, 2001, Perez et al. 2000).

The biochemical consequences of symbioses have been less well investigated for Mediterranean species. A general enhancement of antioxidant defences was described in the demosponge Petrosia ficiformis (Poiret, 1789) as a counteracting response to the more elevated levels of oxygen photosynthetically produced by the cyanobacterium Aphanocapsa feldmanni (Regoli et al. 2000a). The intensity of light irradiance did not appear to be an additional prooxidant stressor, and the levels of antioxidant defences in symbiotic sponges were similar in specimens exposed to high and to low solar irradiance. Compared to tropical symbioses, exposure to UV radiation is more limited at temperate latitudes, and the presence of photosynthesising symbionts appears to be the primary factor inducing an antioxidant response in the Mediterranean sponge $P$. ficiformis.

Mediterranean symbioses also experience marked seasonal variations in seawater temperature, but the influence of these fluctuations has never been assessed in regard to biochemical adaptations to prooxidant challenge. In this study, specimens of Petrosia ficiformis were sampled on a monthly basis from symbiotic colonies and the main antioxidants analysed: superoxide dismutase (SOD, which catalyses the dismutation of $\mathrm{O}_{2}^{-}$to $\mathrm{H}_{2} \mathrm{O}_{2}$ and $\mathrm{O}_{2}$ ), catalase (which reduces $\mathrm{H}_{2} \mathrm{O}_{2}$ to $\mathrm{H}_{2} \mathrm{O}$ and $\mathrm{O}_{2}$ ), glutathione S-transferases (which catalyses conjugation reactions of glutathione to electrophilic centres of organic substrates), glutathione peroxidases (as the sum of Se-dependent and Se-independent forms, which reduce inorganic and organic hydroperoxides with oxidation of reduced glutathione), glutathione reductase (which converts oxidised glutathione GSSG to the reduced and functionally active form GSH). The results for the individual antioxidants were combined with the total oxyradical scavenging capacity (TOSC) which quantifies the capacity of the whole antioxidant system to absorb different forms of oxyradicals such as peroxyl radicals (ROO·) and hydroxyl radicals (HO•).

The aim of this work was to provide a better characterisation of the antioxidant defences in symbiotic colonies of Petrosia ficiformis and to investigate the possible presence of variations reflecting the seasonality of environmental prooxidant factors. The overall results were expected to indicate whether seasonal variation in both prooxidant pressure and sensitivity of 
antioxidant defences might be useful for predicting differential susceptibility to oxidative damages in Mediterranean symbioses.

\section{MATERIALS AND METHODS}

Specimens. Symbiotic specimens of Petrosia ficiformis are easily recognisable by the presence of the autotrophic cyanobacterium Aphanocapsa feldmanni which, concentrated in the symbiocortex immediately below the ectosome, confers a typical red colour to the sponge surface. Symbiotic sponges were collected on a monthly basis from March 2000 to February 2001, at 5 m depth along the rocky cliff of Paraggi (Portofino Promontory, Ligurian Sea); weather conditions prevented collections in October and January. Seawater temperature was measured on each sampling occasion. Data on solar irradiance at sea level were average of 40 yr observations obtained from the Meteorological Observatory of the University of Genoa (Elena et al. 1981). Organisms were collected, frozen in liquid nitrogen and stored at $-80^{\circ} \mathrm{C}$ until processed for analyses. Chlorophyll a concentrations were determined in the symbiocortex of the sponge and expressed as $\mu \mathrm{g} \mathrm{cm}^{-2}$ (Gilbert \& Allen 1973).

Analysis of antioxidant system of Petrosia ficiformis. Biochemical analyses were carried out on 2 different portions of the sponge, the red superficial symbiocortex, which is more exposed to photosynthetically produced oxygen, and the inner white tissue devoid of symbionts. In the red superficial symbiocortex, some contamination of the homogenates by symbionts cannot be completely ruled out; however the absence of any sonication treatment has been indicated to rule out the possibility that, compared to the inner parts, different results in the symbiocortex might reflect an effect of cyanobacteria (Regoli et al. 2000a). Enzymatic activities of cytosolic fractions were determined in samples homogenised (1:4 w/v ratio) in $100 \mathrm{mM}$ Tris-HCl buffer, $\mathrm{pH} \quad 7.5,0.1 \mathrm{mM}$ phenylmethylsulphonyl fluoride (PMSF), $0.1 \mathrm{mg} \mathrm{ml}^{-1}$ bacitracin and 0.008 trypsin inhibitor units (TIU) $\mathrm{ml}^{-1}$ aprotinin (as inhibitors of proteases), $\mathrm{NaCl} 1.5 \%$. After initial centrifugation at $37000 \times g\left(4^{\circ} \mathrm{C}\right)$ for $20 \mathrm{~min}$, the supernatants were further centrifuged at $110000 \times g$ for $1 \mathrm{~h}$, and cytosolic fractions were stored at $-80^{\circ} \mathrm{C}$. Specific spectrophotometric assays were carried out at a constant temperature of $18 \pm 1^{\circ} \mathrm{C}$; assay conditions have been detailed elsewhere (Regoli et al. 2000a). Superoxide dismutase (SOD) (EC 1.15.1.1) was determined following the reduction of cytochrome $C$ with $\mathrm{O}_{2}^{-}$generated by the xanthine oxidase/hypoxanthine system; 1 unit of SOD is defined as the amount of enzyme that results in $50 \%$ reduction of cytochrome $C$, and different sample volumes were used to determine such inhibition of the reaction rate. Catalase activity (EC 1.11.1.6) was measured by the loss of absorbance due to consumption of $\mathrm{H}_{2} \mathrm{O}_{2}$ at $240 \mathrm{~nm}\left(\varepsilon=0.04 \mathrm{mM}^{-1} \mathrm{~cm}^{-1}\right)$. Glutathione S-transferases (GST) (EC 2.5.1.18) were assayed with 1-chloro2,4 -dinitrobenzene (CDNB) as substrate $(\lambda=340 \mathrm{~nm}, \varepsilon=$ $9.6 \mathrm{mM}^{-1} \mathrm{~cm}^{-1}$ ). Glutathione peroxidases (GPx) activities were measured as the sum of Se-dependent (EC 1.11.1.9) and Se-independent (EC 2.5.1.18) forms. The assay is based on a coupled enzyme system, whereby $\mathrm{NADPH}$ is consumed by glutathione reductase to convert the GSSG produced to its reduced form. The decrease of absorbance was monitored at $340 \mathrm{~nm}(\varepsilon=$ $6.22 \mathrm{mM}^{-1} \mathrm{~cm}^{-1}$ ), and cumene hydroperoxide was used as substrate. Glutathione reductase (EC 1.6.4.2.) was measured following NADPH oxidation during the reduction of GSSG $\left(\lambda=340 \mathrm{~nm}, \varepsilon=6.22 \mathrm{mM}^{-1} \mathrm{~cm}^{-1}\right)$. Protein concentrations in cytosolic fractions were determined according to Lowry et al. (1951) using bovine serum albumin (BSA) as the standard.

For measurement of the total oxyradical scavenging capacity, samples were homogenised as previously described for enzymatic activities, except that PMSF and bacitracin were not added to the buffer. The TOSC assay is based on the reaction between different forms of artificially generated oxyradicals (see below) and the substrate $\alpha$-keto- $\gamma$-methiolbutyric acid (KMBA), which is oxidised to ethylene gas (Winston et al. 1998). When cytosolic fractions are added to the system, sample endogenous antioxidants react with generated oxyradicals, thereby competing with KMBA for oxidant scavenging. The time-course of ethylene formation was monitored throughout the duration of the assay by gas chromatographic analyses, and the antioxidant efficiency of a sample was calculated from its ability to inhibit KMBA oxidation by oxyradicals compared to the control reaction (Winston et al. 1998). Since the efficiency of cellular antioxidants varies as a function of the particular oxidants that attack them, we measured the scavenging capacity towards 2 different oxyradicals, namely peroxyl radicals and hydroxyl radicals (Regoli \& Winston 1999). These reactive oxygen species were generated from the thermal homolysis of 2-2'-azo-bis-(2 methylpropionamidine)-dihydrochloride (ABAP) for peroxyl radicals, and through the ironascorbate Fenton reaction for hydroxyl radicals (Regoli \& Winston, 1999); specific assay conditions have been detailed in Regoli (2000). Reactions were conducted at $35^{\circ} \mathrm{C}$ in gas-tight sealed vials, and $200 \mu \mathrm{l}$ aliquots of the head space were analysed at 10 to 12 min intervals for a total duration of $96 \mathrm{~min}$; ethylene production was measured with a Hewlett Packard (HP 4890 series) gas chromatograph equipped with a Supelco SPB-1 capillary column $(30 \mathrm{~m} \times 0.32 \mathrm{~mm} \times 0.25 \mu \mathrm{m})$ and a flame ionisation detector (FID). The oven, injection and FID temperatures were 35,160 and $220^{\circ} \mathrm{C}$ respectively. 
TOSC values were quantified from the equation TOSC $=100-\left(\int \mathrm{SA} / \mathrm{CA} \times 100\right)$, where $\int \mathrm{SA}$ and $\int \mathrm{CA}$ are the integrated areas calculated under the kinetic curve produced during the reaction course for sample (SA) and control (CA) reactions respectively (Winston et al. 1998). For all samples, a specific TOSC (referred to $1 \mathrm{\mu g}$ of protein) was calculated by dividing the experimental TOSC values by the relative protein concentration (in $\mu \mathrm{g}$ ) contained in the assay.

Statistical analyses. The significance of variations analysed for biochemical parameters were investigated by 2-way analysis of variance testing the effect of 'time of collection', 'portion of the tissue' (red or white) and the interaction 'time $\times$ tissue'. The homogeneity of variance was analysed by Cochran's $C$-test, and post hoc tests (Newman-Keuls) were used to discriminate between means of values.

\section{RESULTS}

The 2-way analysis of variance revealed that all biochemical parameters measured in Petrosia ficiformis showed significant variations as a function of sampling period; for some individual enzymes there was high variability between consecutive months, while others showed a more seasonal trend. With the exception of
SOD and GST, antioxidant values differed between the outer red and inner white portions of the sponge, which were also differentially influenced by season (significant interaction 'tissue $\times$ month'). The results of the statistical analysis are summarised in Table 1.

The activities of various antioxidant enzymes are shown in Figs. 1 \& 2. Superoxide dismutase (SOD) fluctuated between sampling periods, with slightly higher values in June to September for the red outer layer (Fig. 1a); SOD values in the white inner portion showed elevated standard deviations and only the values in September were significantly lower.

Clear seasonal variations were observed for catalase (Fig. 1b), which increased significantly in the red outer layer during the summer months and in March, while specimens collected in autumn and winter periods had the lowest activities. The white inner portion of Petrosia ficiformis also showed some changes in this enzymatic activity, but the range of variation was less and generally confirmed lower activity in winter.

Fairly constant values were obtained for GST in the red outer layer of the sponge, while in the inner portion slightly higher activities in March decreased progressively through the summer until autumn; in autumn and winter they remained constant (Fig. 1c). In both the outer and inner portions, there was an increase in GST activitiy in August.

Table 1. Petrosia ficiformis. Results of 2-way ANOVA of antioxidant parameters in red outer layer and white inner tissues sampled in different months. SOD: superoxide dismutase; GST: glutathione S-transferases; GR: glutathione reductase; GPx: glutathione peroxidases; TOSC: total oxyradical scavenging capacity with peroxyl (ROO·) and hydroxyl (HO·) radicals. ns: not significant

\begin{tabular}{|c|c|c|c|c|c|c|c|}
\hline Enzyme & Effect & df effect & MS effect & df error & MS error & $F$ & p-level \\
\hline \multirow[t]{3}{*}{ SOD } & 1 (Tissue) & 1 & 5.0108 & 89 & 2.260029 & 2.2171 & ns \\
\hline & 2 (Month) & 9 & 14.9961 & 89 & 2.260029 & 6.6353 & $<0.000001$ \\
\hline & $1 \times 2($ Tissue $\times$ Month $)$ & 9 & 17.1105 & 89 & 2.260029 & 7.5709 & $<0.000001$ \\
\hline \multirow[t]{3}{*}{ Catalase } & 1 (Tissue) & 1 & 5438.889 & 96 & 61.87228 & 87.90511 & $<0.000001$ \\
\hline & 2 (Month) & 9 & 1639.932 & 96 & 61.87228 & 26.50511 & $<0.000001$ \\
\hline & $1 \times 2($ Tissue $\times$ Month $)$ & 9 & 1415.356 & 96 & 61.87228 & 22.87545 & $<0.000001$ \\
\hline \multirow[t]{3}{*}{ GST } & 1 (Tissue) & 1 & 61.5904 & 96 & 20.01298 & 3.07752 & $\mathrm{~ns}$ \\
\hline & 2 (Month) & 9 & 375.8420 & 96 & 20.01298 & 18.77991 & $<0.000001$ \\
\hline & $1 \times 2($ Tissue $\times$ Month $)$ & 9 & 94.4197 & 96 & 20.01298 & 4.71792 & $<0.00005$ \\
\hline \multirow[t]{3}{*}{ GR } & 1 (Tissue) & 1 & 914.3381 & 96 & 19.67912 & 46.46234 & $<0.000001$ \\
\hline & 2 (Month) & 9 & 189.8796 & 96 & 19.67912 & 9.64878 & $<0.000001$ \\
\hline & $1 \times 2($ Tissue $\times$ Month $)$ & 9 & 507.7521 & 96 & 19.67912 & 25.80156 & $<0.000001$ \\
\hline \multirow[t]{3}{*}{ GPx } & 1 (Tissue) & 1 & 340.4178 & 82 & 23.08471 & 14.74647 & $<0.0005$ \\
\hline & 2 (Month) & 9 & 368.6944 & 82 & 23.08471 & 15.97137 & $<0.000001$ \\
\hline & $1 \times 2($ Tissue $\times$ Month $)$ & 9 & 143.9233 & 82 & 23.08471 & 6.23457 & $<0.00001$ \\
\hline \multirow[t]{3}{*}{ TOSC-ROO• } & 1 (Tissue) & 1 & 426978.9 & 99 & 9989.638 & 42.74218 & $<0.000001$ \\
\hline & 2 (Month) & 9 & 156450.5 & 99 & 9989.638 & 15.66128 & $<0.000001$ \\
\hline & $1 \times 2$ (Tissue $\times$ Month $)$ & 9 & 73094.6 & 99 & 9989.638 & 7.31704 & $<0.000001$ \\
\hline \multirow[t]{3}{*}{ TOSC-HO. } & 1 (Tissue) & 1 & 3090654 & 100 & 20629.13 & 149.8199 & $<0.000001$ \\
\hline & 2 (Month) & 9 & 272099 & 100 & 20629.13 & 13.1900 & $<0.000001$ \\
\hline & $1 \times 2($ Tissue $\times$ Month $)$ & 9 & 186516 & 100 & 20629.13 & 9.0414 & $<0.000001$ \\
\hline
\end{tabular}



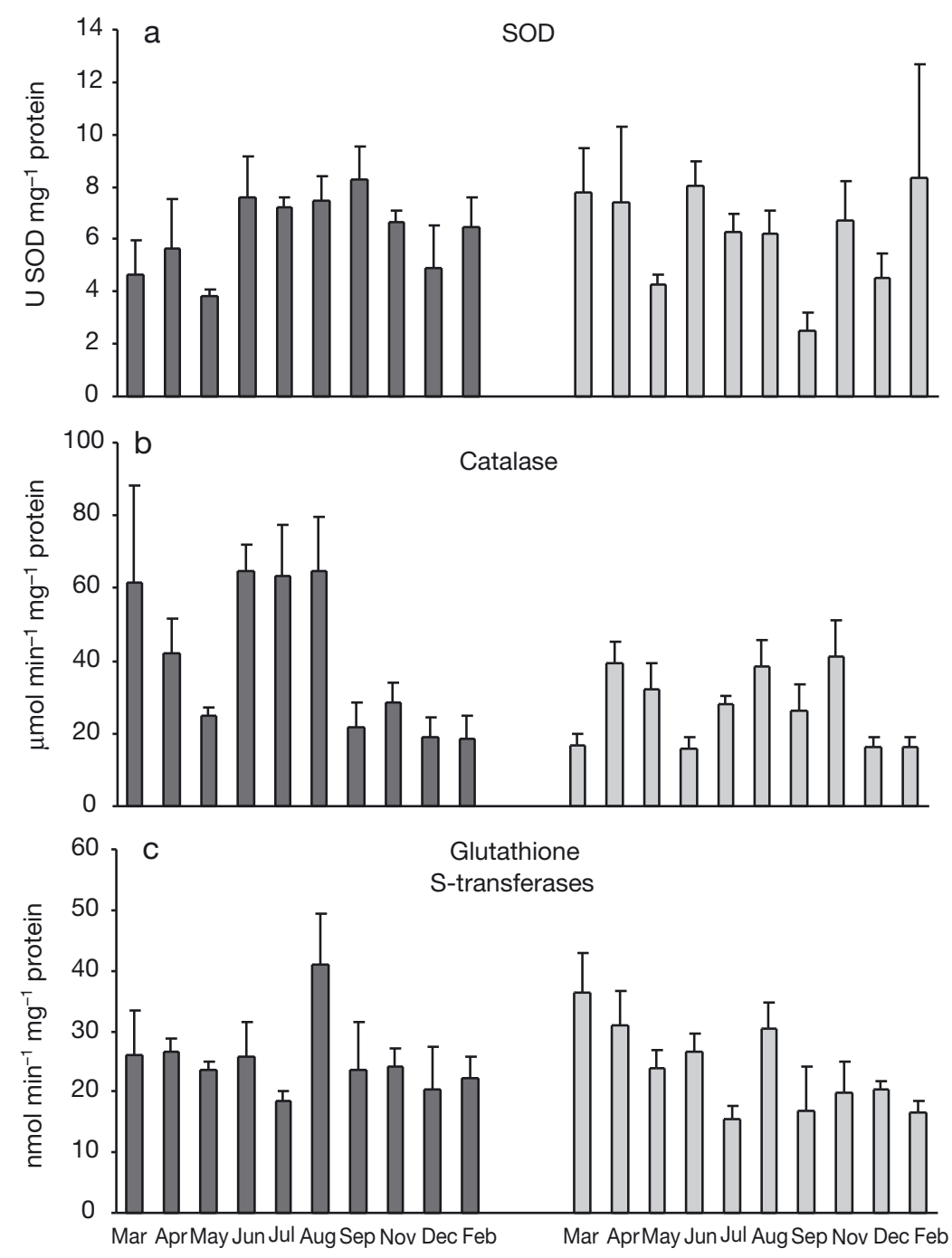

Fig. 1. Petrosia ficiformis. Seasonal variations in antioxidant enzymes in red outer layer (dark grey) and inner tissues (light grey) of symbiotic demosponge. (a) Superoxide dismutase (SOD), (b) catalase, (c) glutathione S-transferases. Means $\pm \mathrm{SD}, \mathrm{n}=10$

Glutathione reductase and glutathione peroxidases showed a similar seasonal trend in the outer red layer of Petrosia ficiformis, with the lowest enzymatic activities in summer (June to August) followed by a sharp increase in September and constant values in the other months (Fig. 2). Fluctuations in these enzymatic systems were lower in the white inner portions of the sponge.

Besides individual antioxidants, tissues of Petrosia ficiformis were also analysed for their total oxyradical scavenging capacity (TOSC) to obtain a more holistic and integrated assessment of the varied capacity of these tissues to absorb different forms of reactive oxygen species (Fig. 3). The white inner portions of the sponge exhibited limited seasonal variation in their absorbant capacity towards peroxyl radicals, with lower values in winter (December to February); even less variable was their capacity to neutralise hydroxyl radicals in the white parts of the sponge, which showed comparable TOSC values throughout all sampling months.

On the other hand, clear seasonal differences were measured in the red outer layer of Petrosia ficiformis: although the trends were slightly different for ROO and $\mathrm{HO}$, the overall capacity to neutralise both these reactive oxygen species was significantly enhanced during the summer months, while the lowest TOSC values were measured in winter (Fig. 3).

Chlorophyll a content in sponge tissues did not exhibit a clear seasonal trend, with fluctuating values and some peaks in spring and September (Fig. 4a); more evident were the seasonal changes measured for superficial solar irradiance and seawater temperatures, with minimum and maximum values in winter and summer months respectively (Fig. 4b,c).

\section{DISCUSSION}

The efficiency of the antioxidant defences of symbiotic invertebrates has been largely documented as being essential to counteract the toxicity of the oxyradicals photosynthetically produced by their symbionts (Shick \& Dykens 1985, Lesser \& Shick 1989, Shick et al. 1995). Although the majority of studies dealt with coral reefs and tropical symbioses, the role of endogenous exposure to ROS and susceptibility to oxidative stress have also recently been documented in a Mediterranean symbiosis by Regoli et al. (2000a), who reported that the demosponge $P$. ficiformis is characterised by a general enhancement of antioxidant defences when symbiotically associated with the cyanobacterium Aphanocapsa feldmanni.

The results of the present study, which analysed a seasonal cycle, add new evidence of the balance between prooxidant pressure and efficiency of antioxidant defences in this Mediterranean symbiotic sponge, which shows significant seasonal changes in antioxidant efficiency. The analysis of individual antioxidants was combined with the measurement of total oxyradical scavenging capacity (TOSC), providing a more holistic assessment of the capacity of 

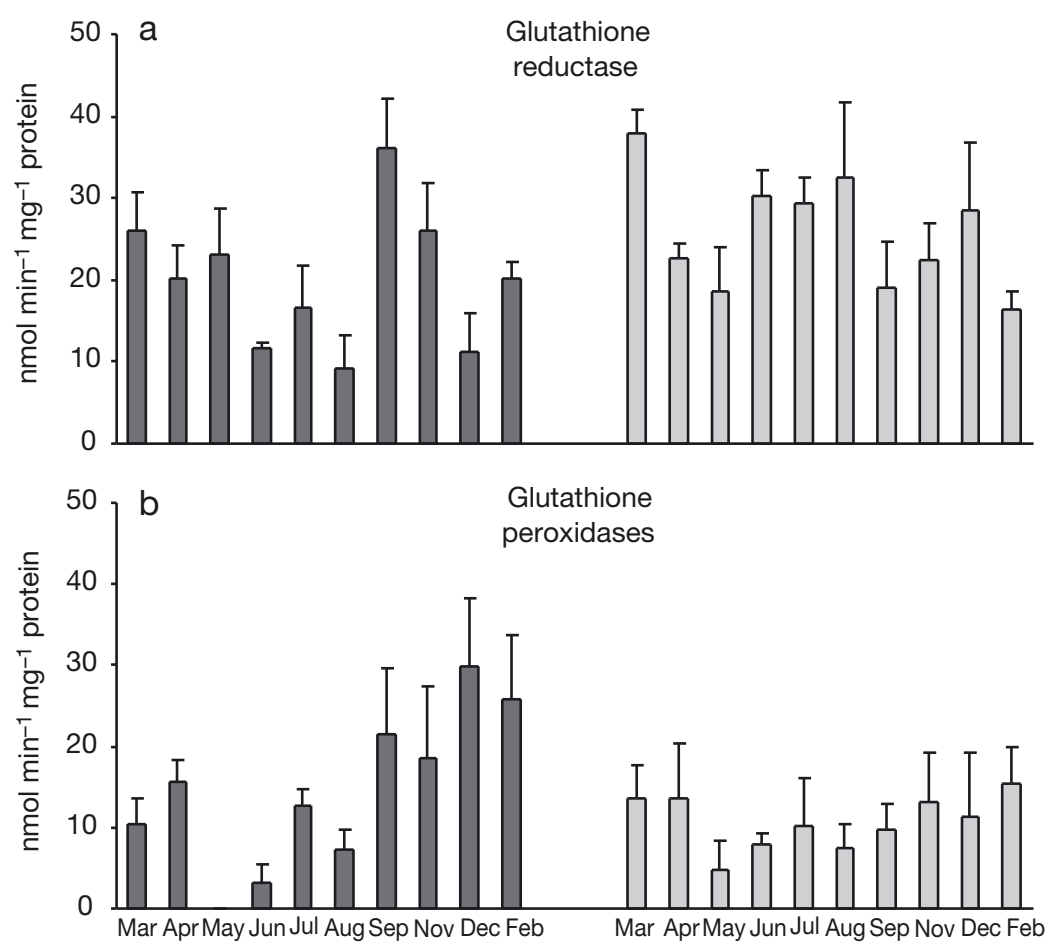

Fig. 2. Petrosia ficiformis. Seasonal variations in antioxidant enzymes in red outer layer (dark grey) and inner tissues (light grey) of symbiotic demosponge. (a) Glutathione reductase, (b) glutathione peroxidases. Means

$$
\pm \mathrm{SD}, \mathrm{n}=10
$$

sponge tissues to absorb different forms of reactive oxygen species (Regoli \& Winston 1998, 1999). While individual antioxidants may be sufficiently sensitive to reveal changes in prooxidant pressure, the overall significance of such variations is difficult to summarise in a single index, especially as some antioxidants are induced and others depleted. TOSC values do not consider the contribution of single antioxidants but represent a quantifiable assessment of susceptibility to oxidative stress. Induced TOSC values have been interpreted as the capacity of a tissue to counteract a prooxidant challenge, while a reduced capacity to neutralise ROS (as peroxyl radicals and hydroxyl radical) has been related to oxidative damages (Regoli 2000, Frenzilli et al. 2001, Regoli et al. 2003).

Fig. 3. Petrosia ficiformis. Seasonal variations in total oxyradical scavenging capacity (TOSC) with (a) peroxyl radicals and (b) hydroxyl radicals in red outer layer (dark grey) and inner tissues (light grey) of symbiotic demosponge. Mean values $\pm \mathrm{SD}, \mathrm{n}=10$
Our results indicate seasonal changes in antioxidants, with a different pattern in different parts of the sponge: more marked variations in the red outer layer than in the white inner portion. In Petrosia ficiformis, symbionts are located in the superficial symbiocortex, and these tissues are thus more directly exposed to photosynthetically produced reactive oxygen species. Once produced by the symbionts, these molecules, and in particular $\mathrm{H}_{2} \mathrm{O}_{2}$, freely diffuse through membranes of the host cytoplasm, acting as prooxidant stressors (Halliwell \& Gutteridge 1999).

In the red outer layer, individual antioxidants varied most during the summer months, with the highest seasonal values for some enzymes (catalase) and the lowest for others (i.e. glutathione reductase, GR, and glutathione peroxidases, GPx). While induction of catalase suggests a counteractive reaction towards increased formation of $\mathrm{H}_{2} \mathrm{O}_{2}$, inhibition of both GR and GPx might indicate some form of toxicity induced by the increased prooxidant challenge. In the red outer layer also, activity of glutathione S-transferases (GST) showed a marked increase in August; note that GST enzymes directly catalyse ROH compounds and may also comprise
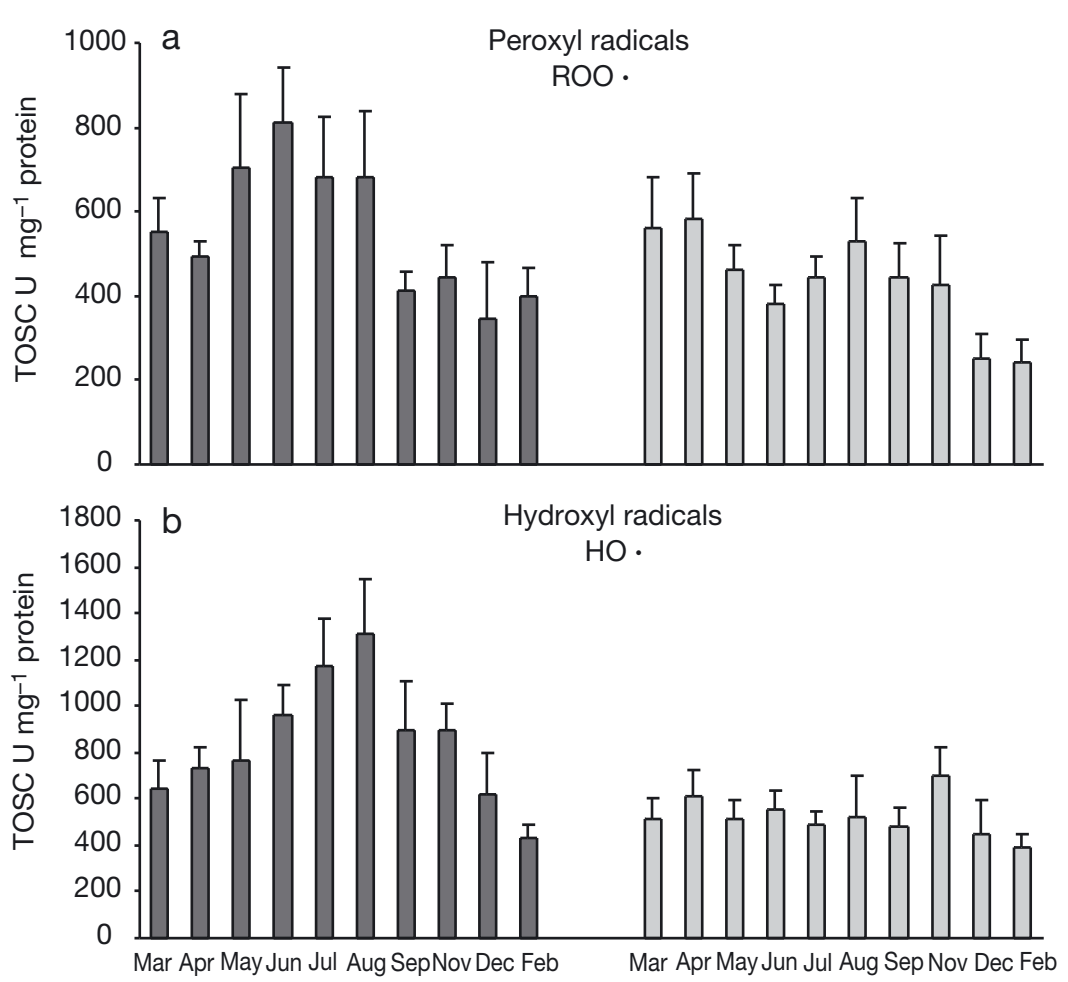
an antioxidant defence. A better understanding of such variations was provided by TOSC analysis, which revealed that the more external tissues of Petrosia ficiformis can significantly increase their capacity to neutralise different oxyradicals (i.e. ROO- and HO·) during the summer months. Antioxidant efficiency appeared to be lowest during the winter period (December to February), confirmed by the results for the white tissues.

The marked increase in catalase and TOSC in summer suggests that formation of hydrogen peroxide in the symbiosis is maximum during this period: catalase directly removes this oxidant species, and the increase in TOSC indicates the necessity to neutralise other forms of ROS which can arise from excess $\mathrm{H}_{2} \mathrm{O}_{2}$ (Regoli et al. 2000b). Among the factors which can modulate formation of $\mathrm{H}_{2} \mathrm{O}_{2}$, is the number of symbionts, light irradiance and seawater temperature (Lesser et al. 1990, Shick 1990, Brown 1997, Downs et al. 2000). Chlorophyll a levels fluctuated between sampling months and an increase in the number of symbionts in summer can be ruled out; the main peaks of chlorophyll $a$ in spring and September are more likely to reflect phytoplankton development in the Ligurian Sea (Innamorati et al. 1990). On the other hand, both solar irradiance and water temperature showed marked seasonal fluctuations that closely resembled those in the capacity of external sponge tissues to neutralise reactive oxygen species. These data support the hypothesis that such environmental factors and their interaction significantly modulate the prooxidant challenge, especially in the outer layer of the symbiocortex, inducing an adaptive response by the host tissues.

In a previous study on Petrosia ficiformis, photosynthetically produced $\mathrm{O}_{2}$, rather than degree of light exposure, appeared the primary factor influencing the biochemical response of the sponge (Regoli et al. 2000a): in the presence of symbionts, colonies increased their antioxidant defences irrespective of solar irradiance. Nonetheless, the effects of photodynamically produced oxyradicals were suggested to influence the antioxidant efficiency of the red outer layer, where such defences might be overstretched above a certain threshold of prooxidant pressure (Regoli et al. 2000a). The potential role of light irradiance as prooxidant stressor was confirmed also by the appearance of degenerative processes (with a concomitant lower efficiency of antioxidant defences) in aposymbiotic colonies moved from the inner part of a submarine cave to a sunlight-exposed cliff (Regoli et al. 2000a). In the present study, fluctuations in solar irradiance reflected the $40 \mathrm{yr}$ average at sea level, thus preventing a statistical comparison with biochemical data; however the trend very closely paralleled the TOSC with peroxyl radicals, also suggesting a specific prooxidant effect of this factor.
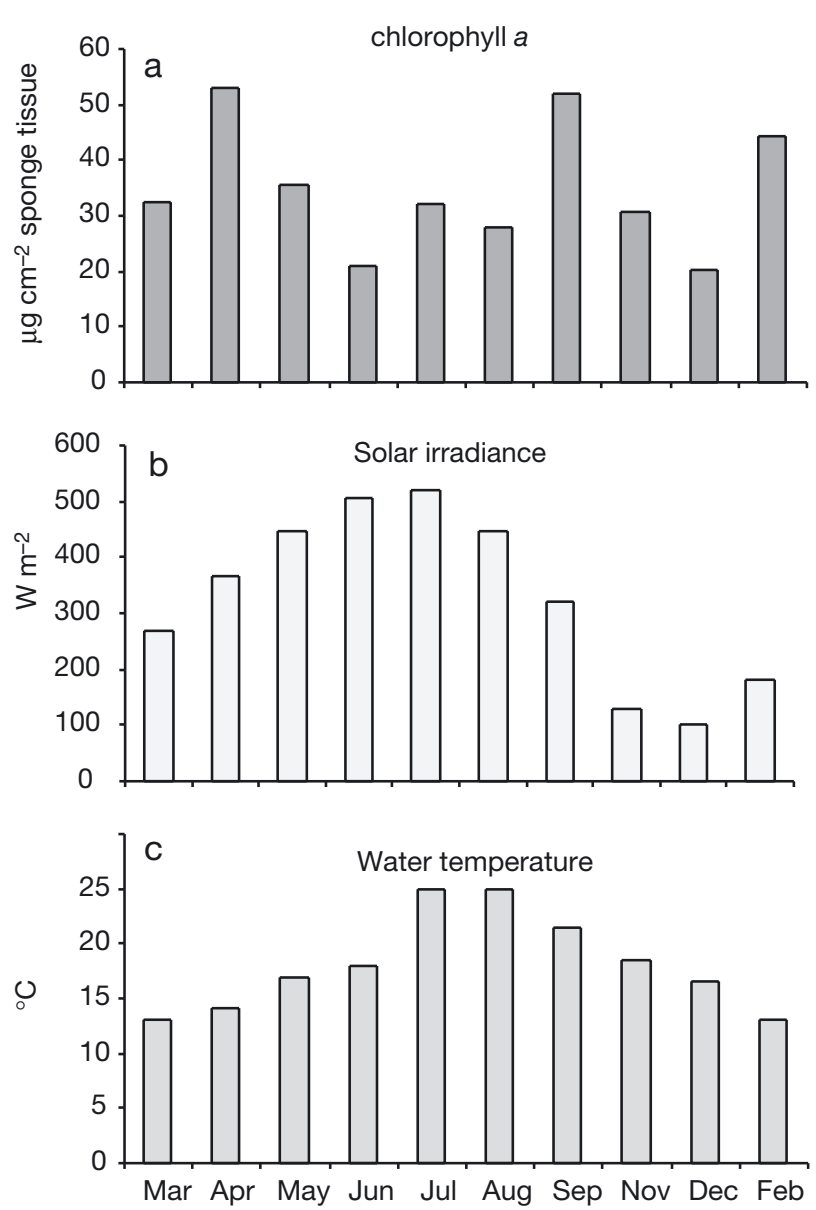

Fig. 4. Seasonal variations in (a) chlorophyll a content of symbiotic demosponge Petrosia ficiformis, (b) surface solar irradiance, and (c) seawater temperature

Our results indicate temperature to be an important factor modulating prooxidant pressure in the Mediterranean symbioses. This result is in accordance with the negative effect of temperature reported for a population of Petrosia ficiformis, of which, after a period of calm and warm water, many specimens had wide white patches on their ectosome, with evident signs of tissutal necrosis (Cerrano et al. 2001). Some effects of temperature and heat stress had recently been reported in the Mediterranean demosponge Axinella polypoides, in which ADP-ribosyl ciclase was activated by a thermosensitive cation channel, leading to intracellular $\mathrm{Ca}^{2+}$ mobilisation (Zocchi et al. 2001). The enhanced levels of cyclic ADP-ribose (CADPR) also caused increased $\mathrm{O}_{2}$ utilisation and consumption by sponge tissues (Zocchi et al. 2002).

In tropical ecosystems, temperature responses and oxidative damages have been observed in symbiotic corals as a result of high temperature and light interactions (Coleman et al. 1995, Brown 1997, Downs et al. 
2000, 2002), and massive bleaching events have been associated with elevated temperature and excessive oxyradical production by the symbionts, which are eventually expelled by the host (Brown et al. 2002a,b, Downs et al. 2002, Douglas 2003). At the cellular level, increased temperature can destabilise the electron transport chain of Photosystem II and the associated heme-catalase (Havaux 1992), thus increasing the generation of $\mathrm{H}_{2} \mathrm{O}_{2}$ which diffuses through the host cytoplasm. The differential sensitivity of corals to heat and light stress and relative bleaching temperature thresholds have been correlated with components of their cellular antioxidant system (Coleman et al. 1995, Brown 1997, Halliwell \& Gutteridge 1999, Hueerkamp et al. 2001, Downs et al. 2002). The ability of corals to increase antioxidant efficiency can reflect a higher resistance to bleaching events. Significantly enhanced levels of antioxidant enzymes were responsible for acquired tolerance to bleaching in some portions of the coral Goniastrea aspera previously exposed to high light levels (Brown et al. 2002a).

A similar model of sensitivity based on antioxidant efficiency could also apply to Mediterranean symbioses. The differences observed in antioxidant defences and oxyradical scavenging capacity between sponge tissues (with and without symbionts) and the influence of season (temperature and light irradiance) are important results of this study: Petrosia ficiformis increased its capacity to neutralise $\mathrm{H}_{2} \mathrm{O}_{2}$ (i.e. catalase) and other important oxyradicals (i.e. $\cdot \mathrm{OH}$ and ROO.) during the warmer months, indicating its potential to counteract increased prooxidant conditions. As a more general application of our results, the observed variability in antioxidant efficiency of $P$. ficiformis indicated that the summer months represent a prooxidant period in the Mediterranean also, suggesting that differential sensitivity to temperature, solar irradiance (and their interaction) can result in oxidative damage in less tolerant species. Since physiological changes and sensitivity vary between species, future research could be directed towards characterising the antioxidant responsiveness and susceptibility to oxidative stress of other Mediterranean sessile organisms, such as anthozoans which have recently been exposed to massive mortality events associated to anomalously high seawater temperatures.

\section{LITERATURE CITED}

Badger MR (1985) Photosynthetic oxygen exchange. Annu Rev Plant Physiol 36:27-53

Brown BE (1997) Adaptations of reef corals to physical environmental stress. Adv Mar Biol 31:222-299

Brown BE, Downs CA, Dunne RP, Gibb SW (2002a) Exploring the basis of thermotolerance in the reef coral Goniastrea aspera. Mar Ecol Prog Ser 242:119-129
Brown BE, Dunne RP, Goodson MS, Douglas AE (2002b) Experience shapes the susceptibility of a reef coral to bleaching. Coral Reefs 21:1191-1226

Cerrano C, Arillo A, Bavestrello G, Calcinai B, CattaneoVietti R, Penna A, Sarà M, Totti C (2000a) Diatom invasion in the antarctic hexatianellid sponge Solymastra joubini. Polar Biol 23:441-444

Cerrano C, Bavestrello G, Bianchi CN, Cattaneo-Vietti R and 8 others (2000b) A catastrophic mass-mortality episode of gorgonians and other organisms in the Ligurian Sea (NW Mediterranean), summer 1999. Ecol Lett 3:284-293

Cerrano C, Magnino G, Sarà A, Bavestrello G, Gaino E (2001) Necrosis in a population of Petrosia ficiformis (Porifera, Demospongiae) in relations with environmental stress. Ital J Zool 68:131-136

Cerrano C, Calcinai B, Cucchiari E, Di Camillo C and 6 others (2004) Are diatoms a food source for Antarctic sponges? Chem Ecol 20:57-64

Coleman JS, Heckathorn SA, Hallberg RL (1995) Heat-shock proteins and thermotolerance: linking molecular and ecological perspectives. Trends Ecol Evol 10:305-306

Douglas AE (2003) Coral bleaching - how and why? Review. Mar Pollut Bull 46:385-392

Downs CA, Mueller E, Phillips S, Fauth J, Woodley CM (2000) A molecular biomarker system for assessing the health of coral (Montastrea favolata) during heat stress. Mar Biotechnol 2:533-544

Downs CA, Fauth JE, Halas JC, Dustan P, Bemiss J, Woodley CM (2002) Oxidative stress and seasonal coral bleaching. Free Radic Biol Med 33:533-543

Dunlap WC, Shick JM (1998) Ultraviolet radiation-absorbing mycosporine-like amino acids in coral reef organisms: a biochemical and environmental perspective. J Phycol 34: 418-430

Dykens JA, Shick JM, Benoit C, Buettner GR, Winston GW (1992) Oxygen radical production in the sea anemone Anthopleura elegantissima and its endosymbiotic algae. J Exp Biol 168:219-241

Elena A, Flocchini G, Pasquale V (1981) Solar global radiation and climate at Genova, Italy. Arch Meteorol Geophys Bioklimatol Ser B 29:129-135

Frenzilli G, Nigro, M, Scarcelli V, Gorbi S, Regoli F (2001) DNA integrity and total oxyradical scavenging capacity (TOSC) in the Mediterranean mussel, Mytilus galloprovincialis: a field study in a highly eutrophicated coastal lagoon. Aquat Toxicol 53:19-32

Gilbert JJ, Allen LH (1973) Chlorophyll and primary productivity of some green fresh-water sponges. Int Rev Ges Hydrobiol 58:633-658

Goreau TJ, Hayes RL (1994) Coral bleaching and ocean 'hot spots'. Ambio 23:176-180

Halliwell B, Gutteridge JMC (1999) Free radicals in biology and medicine. Oxford University Press, New York

Havaux M (1992) Stress tolerance of Photosystem II in vivo. Plant Physiol 100:424-432

Hueerkamp C, Glynn PW, D'Croz L, Mate JL, Colley SB (2001) Bleaching and recovery of five eastern pacific corals in an El Niño-related temperature experiment. Bull Mar Sci 69:215-236

Innamorati M, Lazzara L, Nuccio C, Senesi P, Buracchi, G (1990) Variazioni stagionali e spaziali delle cenosi fitoplanctoniche nel mar Ligure (1979-1982). CEbalia 16: 93-102

Jamieson D, Chance B, Cadenas E, Boveris A (1986) The relation of free radical production to hyperoxia. Annu Rev Physiol 48:703-719

Kushmaro A, Banin E, Loya Y, Stackebrandt E, Rosemberg E 
(2001) Vibrio shiloi sp. nov., the causative agent of bleaching of the coral Oculina patagonica. Int J Syst Evol Microbiol 51:1383-1388

Lesser MP (1996) Elevated temperatures and ultraviolet radiations cause oxidative stress and inhibit photsynthesis in symbiotic dinoflagellates. Limnol Oceanogr 41:271-283

Lesser MP (1997) Oxidative stress causes coral bleaching during exposure to elevated temperatures. Coral Reefs 8: 187-192

Lesser MP, Shick JM (1989) Effects of irradiance and ultraviolet radiation on photoadaptation in the zooxanthellae of Aiptasia pallida: primary production, photoinhibition, and enzymic defences against oxygen toxicity. Mar Biol 102: 243-255

Lesser MP, Stochaj WR, Tapley DW, Shick JM (1990) Bleaching in coral reef anthozoans: effects of irradiance, ultraviolet radiation and temperature on the activities of protective enzymes against active oxygen. Coral Reefs 8:225-232

Lowry OH, Rosenbrough NJ, Farr AL, Randall RJ (1951) Protein measurement with the folin phenol reagent. J Biol Chem 193:266-275

Mehler AH (1951) Studies on reactions of illuminated chloroplasts. I. Mechanisms of the reduction of oxygen and other Hill reagents. Arch Biochem Biophys 33:65-77

Metalpa RR, Bianchi CN, Peirano A, Morri C (2000) Coral mortality in NW Mediterranean. Coral Reefs 19:24

Perez T, Garrabou J, Sartoretto S, Harmelin JG, Francour P, Vacelet J (2000) Mortalité massive d'invertébrés marins: un événement sans précédent en Méditerranée nord-occidentale. CR Acad Sci Ser 3 Sci Vie/Life Sci 323:853-865

Regoli F (2000) Total oxyradical scavenging capacity (TOSC) in polluted and translocated mussels: a predictive biomarker of oxidative stress. Aquat Toxicol 50:351-361

Regoli F, Winston GW (1998) Application of a new method for measuring the total oxyradical scavenging capacity in marine invertebrates. Mar Environ Res 46:439-442

Regoli F, Winston GW (1999) Quantification of total oxidant scavenging capacity (TOSC) of antioxidants for peroxynitrite, peroxyl radicals and hydroxyl radicals. Toxicol Appl Pharmacol 156:96-105

Regoli F, Cerrano C, Chierici E, Bompadre S, Bavestrello G (2000a) Susceptibility to oxidative stress of the Mediterranean demosponge Petrosia ficiformis: role of endosymbionts and solar irradiance. Mar Biol 137:453-461

Regoli F, Nigro, M, Bompadre S, Winston GW (2000b) Total oxidant scavenging capacity (TOSC) of microsomal and

Editorial responsibility: Otto Kinne (Editor),

Oldendorf/Luhe, Germany cytosolic fractions from Antarctic, Arctic and Mediterranean scallops: differentiation between three potent oxidants. Aquat Toxicol 49:13-25

Regoli F, Winston GW, Gorbi S, Frenzilli G, Nigro M, Corsi I, Focardi S (2003) Integrating enzymatic responses to organic chemical exposure with total oxyradical absorbing capacity and DNA damage in the European eel Anguilla anguilla. Environ Toxicol Chem 22:56-65

Richter M, Ruhle W, Wild A (1990) Studies on the mechanisms of photosystem II photoinhibition. II. The involvement of toxic oxygen species. Photosynth Res 24:237-243

Shick JM (1990) Diffusion limitation and hyperoxic enhancement of oxygen consumption in zooxanthellate sea anemones, zoanthids and corals. Biol Bull (Woods Hole) 179:148-158

Shick JM, Dykens JA (1985) Oxygen detoxification in algaeinvertebrate symbioses from the Great Barrier Reef. Oecologia 66:33-41

Shick J, Lesser MP, Dunlap WC, Stochaj WR, Chalker BE, Wu Won J (1995) Depth-dependent responses to solar ultraviolet radiation and oxidative stress in the zooxanthellate coral Acropora microphthalma. Mar Biol 122:41-51

Shick JM, Lesser MP, Jokiel PL (1996) Effects of ultraviolet radiation on corals and other coral reef organisms. Glob Change Biol 2:527-545

Stone L, Huppert A, Rajagopalan B, Bhasin of H, Loya Y (1999) Mass coral reef bleaching: a recent outcome of increased El Nino activity? Ecol Lett 2:325-330

Trench RK (1993) Microalgae-invertebrate symbioses: a review. Endocytobiol Cell Res 9:135-175

Wilkinson CR (1999) Global and local threats to coral reef functioning and existence: review and predictions. Mar Freshw Res 50:867-878

Winston GW, Regoli F, Dugas AJ Jr, Fong JH, Blanchard KA (1998) A rapid gas-chromatographic assay for determining oxyradical scavenging capacity of antioxidants and biological fluids. Free Radic Biol Med 24:480-493

Zocchi E, Carpaneto A, Cerrano C, Bavestrello G and 5 others (2001) The temperature-signaling cascade in sponges involves a heat-gated cation channel, abscisic acid, and cyclic ADP-ribose. Publ Nebraska Acad Sci 98: 14859-14864

Zocchi E, Basile G, Cerrano C, Bavestrello G and 6 others (2002) ABA- and cADPR-mediated effects on respiration and filtration downstream of the temperature-signaling cascade in sponges. J Cell Sci 116:629-636

Submitted: January 22, 2004; Accepted: March 30, 2004

Proofs received from author(s): June 23, 2004 